\title{
Otel Çalışanlarının Kurumsal Sosyal Sorumluluk Algısının İşveren Çekiciliği ve Duygusal Bağlılık Üzerine Etkisi: Kurumsal İtibarın Aracılık Rolü
} (Araştırma Makalesi)

\author{
The Effect of Hotel Employees' Corporate Social Responsibility Perception \\ on Affective Commitment and Employer Attractiveness: The Mediating Role \\ of Corporate Reputation
}

Doi: 10.29023/alanyaakademik.681164

\section{Erhan BOĞAN}

Dr. Öğr. Üyesi, Adıyaman Üniversitesi, Turizm Fakültesi, Turizm Rehberliği Bölümü

ebogan@adiyaman.edu.tr

Orcid No: 0000-0002-8225-4666

Bu makaleye atıfta bulunmak için: Boğan E. (2020). Otel Çalışanlarının Kurumsal Sosyal Sorumluluk Algısının İsveren Çekiciliği ve Duygusal Bağlılık Üzerine Etkisi: Kurumsal İtibarın Aracılık Rolü. Alanya Akademik Bakış, 4(2), Sayfa No 381-398.

\section{Anahtar kelimeler:}

Kurumsal sosyal sorumluluk algisl, algllanan kurumsal itibar, işveren çekiciliği, duygusal bağllık.

Makale Geliş Tarihi: 28.01.2020

Kabul Tarihi:

25.03.2020

Keywords:

Corporate social responsibility perception, corporate reputation, affective commitment, employer attractiveness

\section{ÖZET}

Bu çalışmanın amacı, otel çalışanlarının kurumsal sosyal sorumluluk (KSS) algısının duygusal bağlllık ve işveren çekiciliği üzerine etkisinde algılanan kurumsal itibarın aracılık rolünü incelemektir. Veriler, Türkiye’nin en önemli destinasyonlarından biri olan İstanbul bölgesinde sosyal sorumluluk faaliyetlerinde bulunan beş ylldızlı ü̧̧ otel işletmesinde çalışan 280 kişiden toplanmıştır. Araştırma modeli yapısal eșitlik modellemesinin kısmi en küçük kareler yöntemi kullanilarak test edilmiştir. Yapılan analizler sonucunda, çalı̧̧anların KSS algısının kurumsal itibar üzerine pozitif bir etki oluşturduğu belirlenmiştir. Çalışanların kurumsal itibar algısının hem duygusal bağlllık hem de işveren çekiciliği üzerine pozitif bir etki oluşturduğu belirlenmiştir. Son olarak kurumsal itibar algısl, algılanan KSS işveren çekiciliğinde kismi aracılık rolüne sahipken; algllanan KSS ve duygusal bağlllık ilişkisinde aracılı rolü desteklenmemiştir. Elde edilen bulgular doğrultusunda uygulamacılara yönelik öneriler geliştirilmiştir.

\footnotetext{
ABSTRACT

This study aims to examine the mediating role of perceived corporate reputation in the effect of hotel employees' perception of corporate social responsibility (CSR) on affective commitment and employer attractiveness. Data collected from 280 employees' of three five star hotels which are implementing social responsibility practices in one of Turkey's major destination, Istanbul. The research model was tested using partial least squares method of structural equation modeling. As a result of the conducted analyzes, it was found that the social responsibility perception of the employees has a positive effect on the corporate reputation. Employees' perception of corporate reputation has a positive effect on both affective
} 
commitment and employer attractiveness. Last but not least, corporate reputation plays a partial mediation role in the relation between perceived CSR and employer attractiveness, however its mediating role in the relation between perceived CSR and affective commitment is not supported. In line with the findings, suggestions have been developed for the practitioners.

\section{GİRIŞ}

Avrupa Komisyonu (2001) tarafından "işletmelerin gönüllülük esasına bağlı olarak paydaşları ile etkileşimlerinde ve ticari faaliyetlerinde çevresel ve sosyal sorunları bütünlemesi” olarak tanımlanan kurumsal sosyal sorumluluk (KSS) kavramına araştırmacı ve uygulamacıların ilgisi giderek artmaktadır (Gursoy vd., 2019; Boğan ve Dedeoğlu, 2019; Gürlek ve Tuna, 2019; Boğan vd., 2018a; Kim vd., 2017). Günümüzde birçok otel ve restoran işletmesi, toplumun yaşam kalitesini arttırıcı ve gelecek nesilleri göz önünde bulundurduğunu ortaya koyan ekonomik, sosyal ve çevresel sorumlu girişimleri, farklı iletişim kanalları aracılığıyla paydaşlarına iletmektedir (Boğan ve Dedeoğlu, 2019; Jochim vd., 2015; De Grosbois, 2012). $\mathrm{Bu}$ girişimler sayesinde işletmeler paydaşları nezdinde meşruiyet kazanma ve paydaşların zihninde olumlu etki oluşturma ya da onlardan olumlu geri dönüşler elde etme amacındadır (Ertuna vd., 2019).

KSS faaliyetlerinin stratejik önemini ortaya koymayı amaç edinen ilk çalışmalar, çoğunlukla bu faaliyetleri işletmelerin finansal performansı ile ilişkilendirmiştir. Turizm ve ağırlama endüstrisinde yapılan araştırmalarda sosyal ve çevresel sorumlu faaliyetlerin işletmelerin finansal performansını olumlu etkilediği belirlenmiştir (Rodríguez ve Cruz, 2007; Lee ve Heo, 2009; Qu, 2014). Finansal performansın yanında, paydaş grupları içerisinde müşterilerin KSS faaliyetlerini olumlu algıladığı ve bu algıların müşterilerin işletmeye dönük tutum ve davranışlarına olumlu yansıdığı belirlenmiştir (Huang ve Cheng, 2016; Kim ve Kim, 2016; Gürlek vd., 2017). Ancak müşterilerin dışında, araştırmacılar iç müşteri olarak nitelendirilen çalışanların KSS faaliyetlerini nasıl algıladığı ve bu algılamaların tutum ve davranışlarına nasıl yansıdığının araştırılması gerektiği ifade edilmektedir (Aguinis ve Glavas, 2012; Rhou ve Singal, 2020). Özellikle konuya ilişkin çalışmaların çoğunlukla gelişmiş ülkelerde yapıldığı, gelişmekte olan ya da az gelişmiş ülkelerde çalışanların bu faaliyetlere ne gibi reaksiyonlar gösterdiğinin araştırılması gerektiği tavsiye edilmektedir (Serra-Cantallops vd., 2018). Bununda ötesinde, araştırmacılar KSS ve çalışan geri dönüşleri arasındaki ilişkinin her zaman doğrusal olmadığı, bu ilişkide aracılık rolü üstlenen değişkenlerin keşfedilmesi gerektiğini ifade etmektedir (Gond vd., 2017; Jones vd., 2017; Rupp ve Mallory, 2015).

Hizmet sektöründe yer alan otel işletmelerinde çalışanların tutum ve davranışları, müşterilerin deneyimini şekillendirmede kritik öneme sahiptir. Çalışanlar, hizmet kalitesinin şekillenmesinde, müşteri tatmini ve sadakatinin sağlanmasında büyük öneme sahiptir (Heskett vd., 1994; Boğan ve Dedeoğlu, 2017). Son yıllarda müşterilerin otel işletmelerinden sosyal ve çevresel anlamda sorumlu girişimler beklemesi düşünüldüğünde, otelin sosyal ve çevresel sorumlu davranışlarını müşterilere iletmede çalışanlar önemli bir rol üstlenmektedir (Korschun vd., 2014). Bu noktada ilk olarak çalışanların KSS algısının araştırılması gerekmektedir.

Mevcut çalışma, yukarıda literatürde belirtilen boşlukları doldurma adına, otel çalışanlarının KSS algısını ve bu algının çalışanların tutumlarına nasıl yansıdığını ortaya koymayı amaç 
edinmiştir. Daha açık bir ifadeyle bu çalışmanın amacı, otel çalışanlarının KSS algısının duygusal bağlılık ve işveren çekiciliği ilişkisinde kurumsal itibar algısının aracılık rolünü incelemektir. Mevcut çalışmanın literatüre üç önemli noktada katkı sağlaması beklenmektedir. İlk olarak, çalışanların KSS faaliyetlerine verdikleri geri dönüşler çoğunlukla gelişmiş ülkelerde çalışılmaktadır. Türkiye'nin gelişmekte olan ülkeler arasında yer alması nedeniyle, çalışanların KSS'ye verdikleri reaksiyonların Türkiye'de araştırılması farklı ülkelerde yapılan çalışmaların genellenebilirliğini test etmek için iyi bir fursattır. İkincisi, mevcut çalışanların KSS algısının işveren çekiciliği üzerine etkisini inceleyen araştırma sayısı oldukça kısıtlıdır (Donia vd., 2019). İşgücü bulma maliyeti ve mevcut çalışanları işletmede tutmanın önemi göz önünde bulundurulduğunda (Tracey ve Hinkin, 2008), KSS faaliyetlerinin işveren çekiciliği ve duygusal bağlılık üzerine etkisinin araştırılması oldukça önemlidir. Üçüncüsü, mevcut araştırmada önceki araştırma önerileri dikkate alınarak, KSS ile işveren çekiciliği ve duygusal bağlılık ilişkisinde kurumsal itibarın aracılık rolü incelenmiştir.

\section{KAVRAMSAL ÇERÇEVE ve HIPOTEZLERIN OLUŞTURULMASI}

\subsection{Kurumsal sosyal sorumluluk}

Modern anlamda kurumsal sosyal sorumluluk (KSS) kavramının gelişimi 1950'li yıllara dayanmaktadır. KSS kavramı, işletmelerin toplum üzerine oluşturduğu etkiye vurgu yapan bir kavramdır (Carroll, 1993). Sosyal sorumluluğun temel mantığında, kişinin yaptığı eylemlerin tüm sosyal sistem üzerine etkisini düşünmesi ve bu sistemde yaptığ oluşturduğu etkiden sorumlu olması yer almaktadır (Davis, 1697). Davis ve Blomstrom'e (1975) göre sosyal sorumluluk, karar vericilerin kendi çıkarları ile birlikte toplumun refahını bir bütün olarak koruyan ve geliştiren eylemlerde bulunma yükümlülügüüür. $\mathrm{Bu}$ tanımda sosyal sorumluluğun koruma ve geliştirme gibi iki aktif yönüne işaret edilmiştir. Koruma, bireyin toplum üzerine olumsuz etki oluşturmaktan kaçınması gerektiğine vurgu yaparken; geliştirme, toplum üzerine olumlu etkilerin oluşturulması gerekliliğine dikkat çekmektedir. Bunun yanında KSS, işletme ile toplum arasında yer alan sosyal sözleşmenin yasal boyutundan öte, işletmelerin toplum yararına faaliyetlerde bulunmasını öngörmektedir (Carroll, 1993). Nitekim, Carroll (1979) geliştirdiği modelde işletmelerin sosyal sorumluluk alanlarını dört basamaklı bir piramit dahilinde alttan üste sırasıyla ekonomik, yasal, etik ve gönüllü sorumluluk olarak belirtmiştir.

Ekonomik sorumluluk, işletmelerin mal ya da hizmet üretip satarak kâr elde etmesi sorumluluğu iken, yasal sorumluluk işletmelerin ekonomik faaliyetlerini gerçekleştirirken yasal düzenlemelere uymasıdır. Etik sorumluluk ise, yasal düzenlemelerde yer almasa dâhi, toplum üyeleri tarafindan beklenen veya yasaklanan faaliyetleri ve uygulamaları kapsar. Son olarak gönüllü sorumluluk ise, yalnızca gönüllülük esasına dayanan, işletmelerin zorunlu olmadığı, yasaların gerektirmediği ve genellikle iş açısından etik anlamda beklenmeyen sosyal faaliyetlere katılımdır (Carroll, 1979; 1993). Bu modelde, ekonomik ve yasal sorumluluklar işletmelerin yerine getirmek zorunda olduğu sorumluluklardır. Etik sorumluluklar, işletmelerden beklenenken, gönüllü sorumluluklar ise toplum tarafindan arzulanan sorumluluklardır (Carroll, 1993).

Gelişiminden bu yana, KSS kavramını savunan ve bu kavrama karşı çıkan görüşler her zaman olmuştur. Bu kavrama karşı çıkan taraflar, en temelde klasik ekonomik görüşün işletme yönetiminin sadece işletme sahibi ya da hissedarlarının kârını maksimize etme dışında bir sorumluluğu olmadığını savunmuşlardır. Ünlü ekonomist Milton Friedman (1979) 
işletmelerin sosyal sorunları çözme gibi bir sorumluluğunun olmadığını, bu sorunların çözümümün tamamen hükümetin ve yasal düzenlemelerin sorumluluğunda olduğunu belirtmiştir. Ancak ardından bu görüşünde esnekliğe giden Friedman, işletmelerin sorumluluğunu, ahlaki normlar ve yasal düzenlemeler tarafindan şekillenen toplumun temel kurallarına uyarak mümkün olan en yüksek kârı elde etmek olarak belirtmiştir. Friedman'ın bu görüşü, Carroll'un (1979) piramidinde yer alan ekonomik, yasal ve etik sorumlulukları kapsamaktadır. Ancak karşı çıkılan sorumluluk, işletmelerin gönüllü sorumluluğudur. KSS kavramını savunanlar ise, büyük ölçekli işletme sayısında yaşanan artışın getirdiği önemli insani ve sosyal sorunların işletmelerden bağımsız olarak düşünülemeyeceğini savunmaktadır. İşletme yönetiminin bu sorunları çözme ya da en azından islahına çalışması gerektiği düşünülmektedir. Bu sayede, KSS faaliyetlerinin işletmelere uzun dönemde faydalar sağlayacağı düşünülmektedir.

Nitekim ağırlama ve turizm sektöründe KSS faaliyetlerinin işletmelerin finansal performansı üzerine olumlu etki oluşturduğuna dair ampirik çalışmalar yapılmıştır (Rodríguez ve Cruz, 2007; Lee ve Heo, 2009; Qu, 2014). Spesifik olarak, Rodriguez ve Cruz (2007) otellerin sosyal ve çevresel anlamda sorumlu davranışlar sergilemesinin kârlılık düzeylerini arttırdığını belirlemiştir. Lee ve Heo (2009) otel işletmelerinde KSS faaliyetlerinin firma değerini olumlu etkilediğini belirlemiştir. İşletmelerin finansal performansının yanında, KSS faaliyetlerinin müşterilerin olumlu tutum ve davranışlarına katkı sağladığına dair ampirik çalışmalar da yapılmıştır (Huang ve Cheng, 2016; Kim ve Kim, 2016; Gürlek, Düzgün ve Uygur, 2017). Spesifik olarak, Huang ve Cheng (2016) müşterilerin KSS algısının özdeşleşme üzerine pozitif bir etki oluşturduğunu belirlemiştir. Kim ve Kim (2016) otel müşterilerinin KSS algısının güven ve tatmin üzerine pozitif bir etki oluşturduğunu tespit etmişlerdir. Gürlek ve arkadaşları (2017) İstanbul'da otel müşterilerinin KSS algısının kurumsal imaj ve sadakat üzerine pozitif bir etki oluşturduğunu tespit etmiştir. Bunun yanında araştırmacılar kurumsal imajın, KSS ve müşteri sadakati ilişkisinde kısmi aracılık rolü üstlendiğini belirlemiştir.

\section{2. Çalışanların Kurumsal Sosyal Sorumluluk Algısı ve Algılanan Kurumsal İtibar}

Freeman (1984) tarafından geliştirilen paydaş teorisine göre, işletmeler faaliyet gösterdikleri bölgede aldıkları kararla üzerine etki oluşturduğu ya da karar alma sürecinde etkilendiği hissedarlar, çalışanlar, müşteriler ve toplum gibi paydaşlara karşı sorumludur. Yapılan ampirik çalı̧̧malar paydaş kapsamında çoğunlukla işletmenin hissedarlarına (KSS faaliyetlerinin finansal performansa ve firma değerine etkisi gibi), müşterilerine (kurumsal imaj, sadakat, özdeşleşme) (Rodríguez ve Cruz, 2007; Lee ve Heo, 2009; Qu, 2014; Huang ve Cheng, 2016; Kim ve Kim, 2016; Gürlek vd., 2017) ve topluma odaklanmıştır (Gursoy vd., 2019; Su vd., 2018).

Ancak son birkaç yıldır, hizmet sektöründe müşteri deneyimini etkileyen önemli faktörlerden biri olan çalışanların KSS faaliyetlerine verdikleri geri dönüşleri araştıran çalışmalar yapılmaktadır (Kim vd., 2017; Boğan vd., 2018b; Gürlek ve Tuna, 2019; Boğan ve Dedeoğlu, 2019). Bu çalışmalar içerisinde, Boğan ve Dedeoğlu (2019) Alanya'da otel çalışanlarının topluma ve doğal çevreye yönelik sosyal sorumluluk algısının işletmeye güven üzerine olumlu bir etki oluşturduğunu tespit etmiştir. Gürlek ve Tuna (2019) Antalya'da otel çalışanlarının KSS algısının dışsal prestij, örgütsel özdeşleşme ve işe adanmışlık üzerine olumlu bir etki oluşturduğunu tespit etmiştir. Kim ve arkadaşları (2017) Güney Kore'de lüks otel çalışanlarının KSS algısının iş yaşam kalitesi, duygusal bağlılık ve örgütsel vatandaşlık davranışı üzerine olumlu bir etki oluşturduğunu tespit etmişlerdir. 
Kurumsal itibar kavramı Barnett, Jermier ve Lafferty (2006) tarafından "gözlemcilerin bir işletmeye ilişkin, zaman içinde işletmeye atfedilen finansal, sosyal ve çevresel etkilerin değerlendirmesine dayanan toplu yargısıdır" şeklinde tanımlanmıştır (s. 33). Kurumsal itibar, işletmelere rekabet avantajı sağlayacak kritik öneme sahip soyut kaynaklardan biridir (Siltaoja, 2006). İyi bir kurumsal itibara sahip olan işletmeler, müşteriler ve çalışanlar nezdinde çekici olarak algılanmaktadır (Lange vd., 2011). Hsu (2012)'e göre, KSS faaliyetleri paydaşlar arasında iyi bir itibar oluşturma veya bunu sürdürebilmek için stratejik bir yatırım biçimi olarak görülebilir. Nitekim, yapılan ampirik çalışmalar sosyal ve çevresel anlamda gerçekleştirilen sorumlu kurumsal davranışların işletmenin itibarını güçlendirdiğini göstermektedir (Brammer ve Millington, 2005; Lai vd., 2010). Su ve arkadaşları (2017) Çin'de otel müşterilerinin KSS algısının kurumsal itibar algılamalarını güçlendirdiğini belirlemiştir. KSS ve kurumsal itibar ilişkisi çoğunlukla müşteriler nezdinde incelenmiştir. Bu ilişkiyi çalışan bakış açısıyla ele alınan çalışma sayısı oldukça kısıtlıdır (Fu vd., 2014). İlgili teorik açıklamalar ve yapılan ampirik bulgulara bağlı olarak aşağıda yer alan hipotez kurulabilir;

H1: Çalışanların KSS algısı kurumsal itibar algısını pozitif bir şekilde etkilemektedir.

\subsection{Algılanan Kurumsal İtibar ve Duygusal Bağlılık}

Örgütsel bağlılık kavramı, Porter ve arkadaşları (1974, s. 604) tarafından "bir bireyin belirli bir organizasyonla özdeşleşmesinin ve bu organizasyona bağlı olmasının göreceli gücü” olarak tanımlamaktadır. Allen ve Meyer (1990) örgütsel bağlılık kavramının devam, normatif ve duygusal olmak üzere üç boyutu olduğunu belirtmiştir. Buna göre devam bağlılığı, bireyin işletmeden ayrılma durumunun kendisine getireceği yüksek maliyetlerin farkında olması nedeniyle organizasyon üyeliğini sürdürme durumudur. Normatif bağlılık ise, bireyin işletmeye bir vefa borcu hissetmesi sonucunda üyeliğini sürdürmesi durumudur. Son olarak duygusal bağlılık ise, çalışanın çalıştığı işletmeye karşı duygusal bağlanması, işletme ile özdeşleşmesi ve işletmenin bir üyesi olmaktan hoşnut olma durumudur (Allen ve Meyer, 1990). Çalıştıkları işletmeye duygusal anlamda bağlı olanlar istedikleri için; normatif anlamda bağlı olanlar ahlaki bir sorumluluk hissettikleri için; ve devam bağlılığı güçlü olanlar ise ihtiyaç duydukları için organizasyonda kalma eğilimindedir (Allen ve Meyer, 1990). Bu bağlılık türleri içerisinde, duygusal bağlılık kavramı çalışan-organizasyon arasındaki psikolojik ilişkide en kuvvetli öncül olarak kabul edilmektedir (Buonocore, 2010).

Sosyal kimlik teorisine göre (Tajfel ve Turner, 1985), insanlar doğuştan kendilerini ve başkalarını bir takım sınıf ya da kategorilere ayırırlar. Bu kategoriler ya da sınıflar, bireyin kendisini sosyal çevresinde konumlandırmasında dolayısıyla benlik ya da kimlik gelişimi üzerine etkilidir. Bu kategorilerden birisi, kişinin mensubu olduğu organizasyondur. Yani bireyin çalıştığı ortam, kendisini sosyal çevresinde tanımlamasında etkilidir. Kurumsal itibarı yüksek bir işletmede çalışmak, bireyin çalıştığı işletmeden gurur duymasına ve sonuç olarak olumlu tutum ve davranışların sergilenmesine katkı sağlar (Dutton vd., 1994; Maignan ve Ferrell, 2001). Fu, Li ve Duan (2014) Çin'de otel çalışanlarının kurumsal itibar algısının örgütsel bağlılık üzerine etkili olduğu sonucunu elde etmiştir. Alnıaçık ve arkadaşları (2011) akademisyenlerin kurumsal itibar algısının duygusal bağlılık üzerine pozitif bir etki oluşturduğunu tespit etmişlerdir. Benzer şekilde, Arıkan ve arkadaşları (2016) Türkiye'nin önde gelen işletme çalışanlarından topladıkları verilerle yaptıkları analiz sonucunda, çalışanların kurumsal itibar algısının iş tatmini, örgütsel bağlılık üzerine pozitif bir etki 
oluşturduğunu tespit etmişlerdir. Yapılan teorik açıklamalar ve ampirik çalışmalara dayalı olarak aşağıda yer alan hipotez kurulabilir;

H2: Çalışanların kurumsal itibar algısı duygusal bağlılı̆̆ı pozitif bir şekilde etkilemektedir.

\subsection{Algılanan Kurumsal İtibar ve İşveren Çekiciliği}

İşveren çekiciliği kavramı, "potansiyel bir çalışanın belirli bir organizasyonda çalışırken göreceği faydaların düşünülmesi” ş̧eklinde tanımlanmaktadır (Berthon vd., 2005, s. 156). Günümüz rekabet ortamında, işgücünü işletmeye çekme ve işletmede kalmalarını sağlama önemli bir rekabet avantajı sağlamaktadır (Greening ve Turban, 2000). Sinyal verme teorisine (Rynes, 1991) göre, potansiyel bir çalışan, işletmede çalışması halinde nasıl bir iş ortamının kendisini beklediği hakkında birtakım ipuçları aramaktadır. Bu sinyal ya da ipuçlarına bağlı olarak, kişi işletmeye iş başvurusunda bulunmaktadır. İşletmenin kurumsal itibarı bu sinyallerden ya da ipuçlarından birisidir. Potansiyel bir çalışan, kurumsal itibarı yüksek bir işletmede çalışarak, arzu ettiği faydaları elde edebileceğini düşünmektedir (Turban ve Greening, 1997; Cable ve Turban, 2003). Gatewood ve arkadaşları (1993) bir işletmenin çekiciliğinin itibarı ile ilişkili olduğunu tespit etmişlerdir. Behrend, Baker ve Thompson (2009), kurumsal itibarın bireylerin iş başvurusu yapma niyeti üzerine etkili olduğunu ortaya koymuşlardır. Yapılan teorik açıklamalar ve ampirik çalışmalara dayalı olarak aşağıda yer alan hipotez kurulabilir;

H3: Çalışanların kurumsal itibar algısı işveren çekiciliğini pozitif bir şekilde etkilemektedir.

\subsection{Algılanan Kurumsal İtibarın Aracilık Rolü}

Mevcut çalışmada, algılanan kurumsal itibar sosyal sorumluluk faaliyetlerinin önemli bir nihai değişkeni ve duygusal bağlılık ile işveren çekiciliğinin önemli bir öncülü olması nedeniyle, kurumsal itibarın aracılık rolü üstlenmesi beklenebilir. Nitekim, Turban ve Greening (1997)'e göre, sosyal ve çevresel anlamda sorumlu davranışlar sergileyen işletmelerin kurumsal itibarı güçlenecek ve bu durum işvereni işgücü nezdinde çekici kılacaktır. Benzer şekilde, sosyal kimlik teorisine göre, kişinin öz imajı işvereninin itibar ve imajından etkilenmektedir. Sosyal sorumluluk faaliyetleri ile güçlü bir itibara sahip olan işverenler, potansiyel işgücü nezdinde çekici algılanacaktır (Greening ve Turban, 2000). Gürlek ve Tuna (2019) çalışanların KSS algısının işe adanmışlık üzerine etkisinde çalışanların dışsal prestij algısının aracılık rolü üstlendiği belirlemişlerdir. Behrend, Baker ve Thompson (2009), işletmelerin çevresel anlamda sorumlu davranışlarını içeren mesajların iş başvurusu yapma niyeti üzerine etkisinde kurumsal itibarın aracılık rolü üstlendiğini ortaya koymuşlardır. Yapılan açıklamalara dayalı olarak aşağıda yer alan hipotez kurulabilir;

H4ab: Çalışanların kurumsal itibar algısı, a) algılanan KSS ve duygusal bağlılık ilişkisinde; b) algılanan KSS ve işveren çekiciliği ilişkisinde aracılık rolü üstlenmektedir.

Şekil 1'de oluşturulan araştırma modeli yer almaktadır. Buna göre, çalışanların KSS algısının kurumsal itibarı; kurumsal itibarın da duygusal bağlılık ve işveren çekiciliğini etkilemesi beklenmektedir. Bunun yanı sıra kurumsal itibarın, kurulan modelde aracılık rolü üstlenmesi beklenmektedir. 


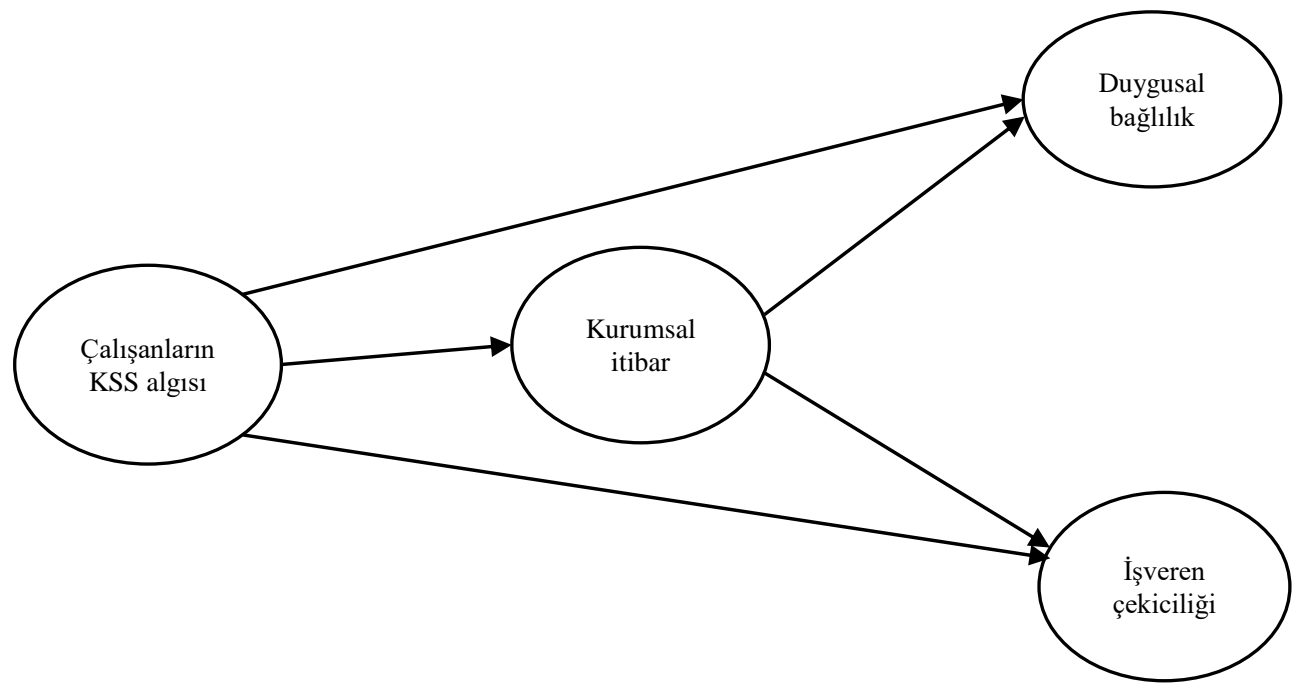

Şekil 1. Araştırma modeli

\section{YÖNTEM}

\section{1. Ölçüm Aracı}

Çalışmada veri toplama aracı olarak anket kullanılmıştır. Anketin ilk bölümünde, çalışanların KSS algısı ve algılanan kurumsal itibarı ölçen ifadelere yer verilmiştir. İkinci bölümde ise, çalışanların duygusal bağlılık ve işveren çekiciliğini ölçen ifadeler yer almaktadır. Son bölümde ise, katılımcıların demografik özelliklerini ortaya koyacak sorulara yer verilmiştir. Çalışanların kurumsal sosyal sorumluluk algısını ölçmek için Panagopoulos, Rapp ve Vlachos (2016) tarafından adapte edilmiş dört ifadeli ölçek kullanılmıştır. Çalışanların duygusal bağlılık tutumunu ölçmek için Meyer, Allen ve Smith (1993) tarafından geliştirilen altı ifadeli ölçek kullanılmıştır. İşveren çekiciliğini ölçmek için Donia ve arkadaşlarının (2019) çalışmalarında kullandığı beş ifadeli ölçek kullanılmıştır. Son olarak, algılanan kurumsal itibarı ölçmek için ise, Bartels, Pruyn ve Jong (2009) tarafından geliştirilen üç ifadeli ölçek kullanılmıştır. Çalışma kapsamında kullanılan tüm ölçekler, güvenilir ölçeklerdir. Çalışmada ilgili kavramlar 5'li likert tipi ölçek ile ölçülmüştür (kesinlikle katılmıyorum-kesinlikle katıliyorum).

\section{2. Örneklem}

Çalışmanın verileri, Türkiye'nin önemli destinasyonlarından biri olan İstanbul'da faaliyet gösteren beş yıldızlı üç otel işletmesi çalışanlarından toplanmıştır. Bu üç otel işletmesinin seçilmesinin temel nedeni, her üç otelin sosyal ve çevresel anlamda sorumluluk faaliyetlerine aktif katılım sağlamalarıdır. İlk olarak araştırmacı tarafından her üç otelin yöneticisi aranmış ve randevu talep edilmiştir. Görüşme esnasında yöneticiler, çalışmanın amacı, anket formu, sonuçların nerede kullanılacağı gibi konular hakkında bilgilendirilmiştir. Her üç yöneticinin çalışmaya katılım sağlamayı kabul etmesi sonrası, anketler insan kaynakları yöneticilerine teslim edilmiştir. Anketler, Park ve Levy (2014) çalışması örnek alınarak, sadece ön büro, kat 
hizmetleri ve yiyecek-içecek departmanı çalışanlarına uygulanmıştır. Üç otel işletmesinde çalışma kapsamına girebilecek toplam 498 çalışan vardır. Çalışmada tüm çalışanlara ulaşma amacıyla her üç otele 170 anket dağıtılmıştır. Dağıtılan anketler bir hafta sonra toplanmıştır. Toplanan anket sayısı 321'dir. Dolayısıyla geri dönüş oranı \%64'tür. Elde edilen anketlerden bazılarının fazla kayıp değer içermesi (18 adet), bazılarında ise uç değerlerin olması (23 adet) sebebiyle analiz dişı bırakılmıştır. Analizler, toplam 280 deneğin verdiği cevaplardan oluşan veri setiyle yapılmıştır.

\subsection{Veri Analizi}

Araştırmanın modelini test etmek için yapısal eşitlik modellemesinin kısmi en küçük kareler yöntemi (KEKK-YEM) kullanılmıştır. KEKK-YEM, örnekleme sayısının nispeten küçük olduğu, kompleks modelleri test etmede oldukça etkili bir yöntemdir. Bunun yanında, bu yöntemde veri seti için normal dağılım şartı aranmamaktadır (Hair vd., 2017). Çalışmanın modeli test edilirken, SmartPLS paket programından faydalanılmıştır. Ek olarak, çalışmada yer alan aracılık modelini test etmek için Baron ve Kenny'nin (1986) yaklaşımının aksine Zhao, Lynch ve Chen (2010) tarafindan tavsiye edilen önyükleme (bootstrapping) yöntemi kullanılmıştır. Bu yöntemde aynı şekilde normal dağılım şartı aranmaz ve küçük örneklemler için oldukça uygundur (Hair vd., 2017).

\section{BULGULAR}

\subsection{Demografik Bulgular}

Katılımcıların 160'ı erkek, 164'ü evlidir. Eğitim durumu incelendiğinde, katılımcıların 99'u lise, 78'i önlisans, 62'si lisans, 37'si ilköğretim ve 4'ü lisansüstü eğitim mezunudur. Katılımcıların yaş gurubuna göre dağılımı incelendiğinde, 124'ü 30-39, 100'ü 21-29, 46'sı 40-49 yaş grubu arasındadır. Katılımcıların çalıştıkları departmanlara dağılımları incelendiğinde ise, 112 kişi kat hizmetleri, 90 kişi yiyecek-içecek departmanı ve 78 kişi ön büro departmanında çalışmaktadır. Katılımcılardan 217 kişi yönetsel olmayan organizasyon kademesinde, 48'i ilk kademe yönetici olarak değerlendirilebilecek şef düzeyinde, 14'ü ise orta düzey yönetim kademesi olarak değerlendirilebilecek departman müdürü kademesinde çalışmaktadır.

\section{2. Ölçüm Modeli}

Yapısal eşitlik modellemesi ölçüm modeli ve yapısal model olmak üzere iki yapıdan oluşmaktadır (Hair vd., 2014). KEKK-SEM yönteminde, modeli değerlendirmede ilk olarak ölçüm modeli ardından yapısal model test edilir. Ölçüm modeli, ölçümün kalitesini test etmek için kullanılır. Yansıtan değişkenlerden oluşan ölçüm modelini test etmede kullanılan temel ölçütler güvenirlik, yakınsama geçerliliği ve ayırt edici geçerliliktir. Güvenirlik, geçerlilik için temel koşuldur. Güvenirliği test etmek için birleşik yapı güvenirliği (BYG) kullanılmıştır. Cronbach' $\alpha$, ilgili yapıyı ölçen ifade sayısına duyarlı olduğu için daha uygun bir teknik olan BYG kullanılmıştır (Hair vd., 2017). BYG için 0.70 ile 0.90 arasındaki değerler (Hair vd., 2017) güvenirlik için tatmin edicidir. Tablo 1 incelendiğinde, ilgili dört yapının da BYG değeri 0.81 ile 0.88 arasında değişmektedir. Dolayısıyla ölçüm modelinde güvenirliğin sağlandığı söylenebilir. 
Tablo 1. Ölçüm Modeli Sonuçları

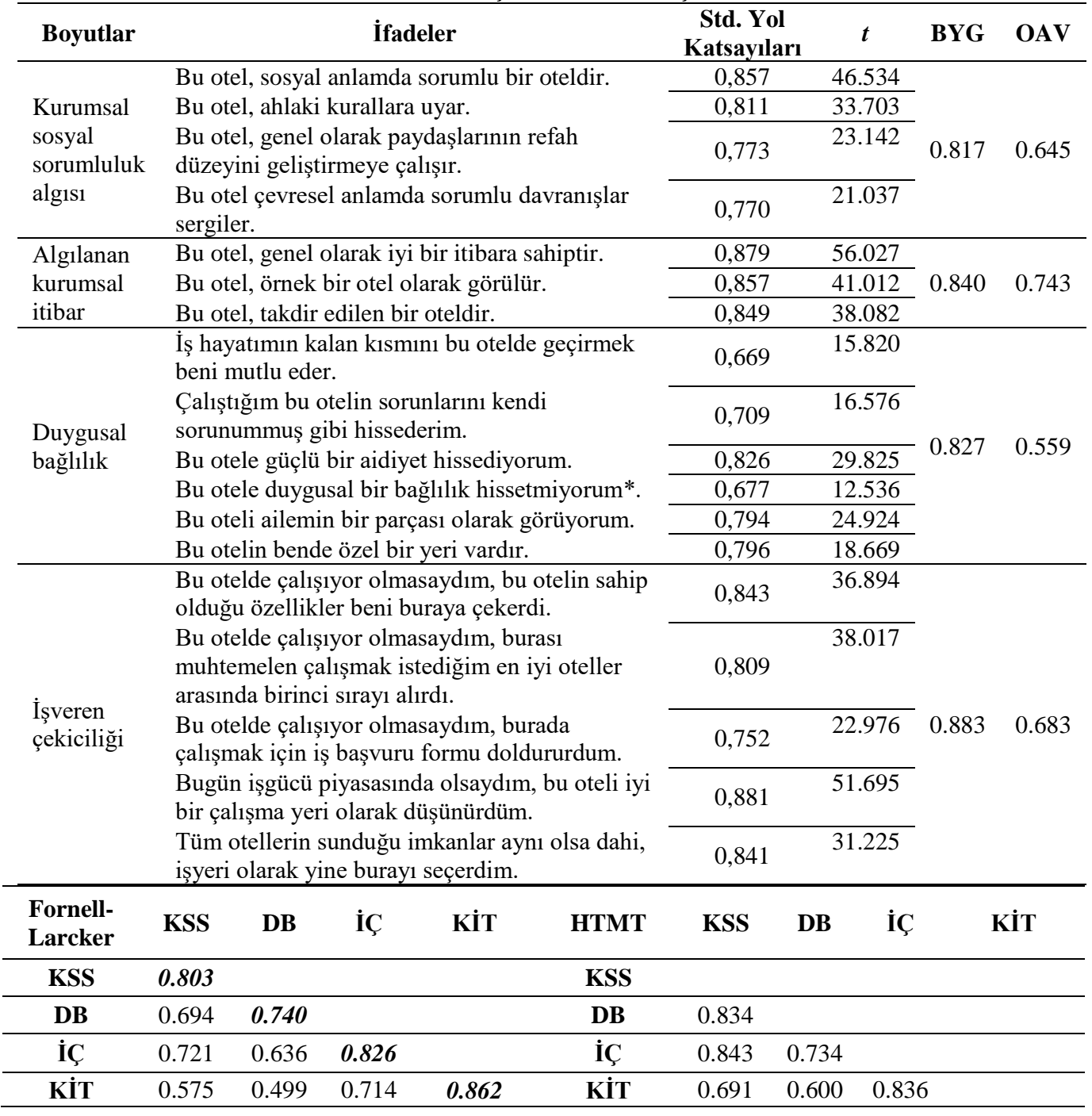

Not. KSS: çalışanların kurumsal sosyal sorumluluk algısı; DB: duygusal bağlılık; İÇ: işveren çekiciliği; KİT: algılanan kurumsal itibar. Kalın ve italik yazılan sayılar, ilgili yapının ortalama açıklanan varyans değerinin karesini temsil etmektedir. * ters kodlanmıştır.

Yakınsama geçerliliği, bir yapıyı ölçmede kullanılan göstergelerin aynı yapıyı ölçen diğer göstergelerle pozitif ilişkisini göstermektedir. Yansıtan değişkenlerde yakınsama geçerliliği için en güçlü ölçütlerden biri ortalama açıklanan varyans (OAV) değeridir. OAV değeri 0.50 ve üzerinde olmalıdır (Hair vd., 2017). Tablo 1 incelendiğinde, ilgili dört yapının da OAV değeri 0.50'nin üzerindedir. Ayırt edici geçerlilik ise, bir yapının ampirik standartlara göre diğer yapılardan gerçekte ne kadar farklı olduğunu göstermektedir. Ayırt edici geçerlilikte temel ölçütlerden biri Fornell ve Larcker (1981) kriteridir. Buna göre, bir yapının OAV 
değerinin karekökü, ilgili yapının diğer yapılarla olan korelasyon değerinden yüksek olmalıdır. Bir diğer ölçüt ise, Henseler ve arkadaşları (2015) tarafından geliştirilen HTMT kriteridir. Buna göre, HTMT değerinin 0.90'dan büyük olmaması gerekmektedir. Tablo 1 incelendiğinde, ölçüm modelinde hem Fornell ve Larcker (1981) hem de HTMT kriterinin sağlandığ1 görülmektedir. Sonuçlar bir bütün olarak değerlendirildiğinde, ölçüm modelinin güvenirlik ve yapı geçerliliği ölçütlerini sağladığı söylenebilir.

\subsection{Yapısal Model}

Ölçüm modeli test edildikten sonra yapısal model test edilmektedir. Yapısal modelde referans olarak değerlendirilebilecek en önemli ölçütler, açıklanan varyansı temsil eden $R^{2}$, etkinin büyüklüğünü temsil eden $f^{2}$ ve kestirim uygunluğu olarak kullanılan $Q^{2}$ 'dir (Hair vd., 2017). Yapısal modelde yol katsayılarına ilişkin t değerlerini bulmak için önyükleme (bootstrapping) yeniden örnekleme yöntemi kullanılmıştır. Bu teknikte alt örneklem değeri olarak Hair ve arkadaşlarının (2014) tavsiyesi esas alınarak 5.000 olarak belirlenmiştir. Yapısal modele ilişkin sonuçlar Tablo 2'de yer almaktadır. Yapılan analiz sonucunda, çalışanların KSS algısının kurumsal itibar algısını pozitif ve anlamlı bir şekilde etkilediği görülmektedir $(\beta=.575, t=11.895 \mathrm{p}<.05)$. İkinci olarak, çalışanların kurumsal itibar algısının duygusal bağlılığı pozitif ve anlamlı olarak etkilediği belirlenmiştir $(\beta=.149, t=2.308 \mathrm{p}<.05)$. Son olarak, çalışanların kurumsal itibar algısının işveren çekiciliğini pozitif ve anlamlı bir şekilde etkilediği belirlenmiştir $(\beta=.446, t=8.933 \mathrm{p}<.05)$. Buna göre, $\mathrm{H}_{1}, \mathrm{H}_{2}$ ve $\mathrm{H}_{3}$ hipotezleri ampirik olarak desteklenmiştir.

Tablo 2. Yapısal Model Sonuçları

\begin{tabular}{lcccccccc}
\hline \multicolumn{1}{c}{ İlişki } & $\begin{array}{c}\text { Yol } \\
\text { katsayıları }\end{array}$ & \multirow{2}{*}{ teğeri } & $\begin{array}{c}\mathrm{p} \\
\text { değeri }\end{array}$ & $\begin{array}{c}\text { Güven aralığı } \\
\mathrm{BC}\end{array}$ & VIF & $R^{2}$ & $f^{2}$ & $Q^{2}$ \\
\hline $\mathrm{KSS} \rightarrow \mathrm{KİT}$ & .575 & 11.895 & .000 & {$[.469 / .660]$} & 1.000 & .328 & .494 & .225 \\
\hline $\mathrm{KİT} \rightarrow \mathrm{DB}$ & .149 & 2.308 & .021 & {$[.025 / .277]$} & 1.494 & .493 & .030 & .253 \\
\hline $\mathrm{KİT} \rightarrow$ İÇ & .446 & 8.933 & .000 & {$[.346 / .541]$} & 1.494 & .651 & .385 & .412 \\
\hline
\end{tabular}

Not: KSS: çalışanların kurumsal sosyal sorumluluk algısı; DB: duygusal bağlılık; İÇ: işveren çekiciliği; KİT: algılanan kurumsal itibar.

Tablo 2'de modelin yordama gücünün bir ölçüsü olarak kullanılan $R^{2}$ incelendiğinde, algılanan kurumsal itibarın \%32'si, duygusal bağlılığın \%49'u ve son olarak işveren çekiciliğinin \%65'i açıklanmıştır. Yapısal model için gösterge kabul edilen bir diğer referans değeri Cohen (1988) tarafindan geliştirilen $f^{2}$ 'dir. Cohen'e (1988) göre, 0.35, 0.15 ve 0.02 sırasıyla büyük, orta ve düşük etkiyi temsil etmektedir. Tablo 2'de görüldüğü üzere, çalışanların KSS algısı kurumsal itibar algısı üzerine yüksek etkiye sahiptir $\left(f^{2}=.49\right)$. Çalışanların kurumsal itibar algısı işveren çekiciliği üzerine yüksek $\left(f^{2}=38\right)$; duygusal bağlılık üzerine orta derece bir etkiye sahiptir $\left(f^{2}=.03\right)$. Son olarak, modellerin tahmini geçerliliğini değerlendirmek için, atlama mesafesi altı olan bir göz bağlama (blindfolding) prosedürü gerçekleştirilmiştir. Bunun için modelin tahmin yeteneğini test etmek için StoneGeiser'in $Q^{2}$ testi kullanılmıştır (Geisser, 1974; Stone, 1974). $Q^{2}$ değerinin sıfırdan büyük olması modelin örnek dişı tahmin gücünün yüksek olduğunu göstermektedir (Henseler et al., 2009). Tablo 2 incelendiğinde, $Q^{2}$ değerlerinin sıfirdan büyük olduğu görülmektedir. 


\subsection{Aracılık Modeli}

Araştırma modelinde aynı zamanda algılanan kurumsal itibarin aracılık rolü incelenmiştir. Bunun için Zhao ve arkadaşları (2010) ve Nitzl ve arkadaşları (2016) tarafindan tavsiye edilen süreç dikkate alınmıştır. İlk olarak algılanan kurumsal itibarın dolaylı etkisinin anlamlılığı incelenmiştir. Ardından, bağımsız değişken olarak KSS algısının hem duygusal bağlılık hem de işveren çekiciliği üzerine doğrudan etkisinin anlamlılı̆̆ı incelenmiştir. Aracılık modelinin sonuçları Tablo 3 'te yer almaktadır. Tabloda görüldüğü üzere çalışanların KSS algısının duygusal bağlılık $(\beta=.086, t=2.143 \mathrm{p}<.05)$ ve işveren çekiciliği üzerine dolaylı etkisi anlamlıdır $(\beta=.257, t=6.628 \mathrm{p}<.05)$. Aynı zamanda, KSS algısının duygusal bağlılık $(\beta=.694, t=16.058 \mathrm{p}<.05)$ ve işveren çekiciliği $(\beta=.721, t=21.927 \mathrm{p}<.05)$ üzerine doğrudan etkisi de anlamlıdır. Dolayısıyla algılanan kurumsal itibar, kısmi aracılık rolüne sahiptir denilebilir.

Tablo 3. Aracılık Modeli Sonuçları

\begin{tabular}{|c|c|c|c|c|c|c|c|c|c|}
\hline & $\begin{array}{c}\text { Doğrudan } \\
\text { etki }\end{array}$ & $\begin{array}{c}\text { Doğrudan } \\
\text { etki (\%95 } \\
\text { güven } \\
\text { aralığı) }\end{array}$ & $\begin{array}{c}\mathrm{t} \\
\text { değeri }\end{array}$ & $\underset{\text { değeri }}{p}$ & $\begin{array}{c}\text { Dolayli } \\
\text { etki }\end{array}$ & $\begin{array}{l}\text { Dolaylı } \\
\text { etki (\%95 } \\
\text { güven } \\
\text { aralığı) }\end{array}$ & $\stackrel{\mathrm{t}}{\text { değeri }}$ & $\underset{\text { değeri }}{\mathrm{p}}$ & VAF \\
\hline $\mathrm{KSS} \rightarrow \mathrm{DB}$ & .694 & {$[.179 / .394]$} & 16.058 & .000 & .086 & {$[.014 / .169]$} & 2.143 & .032 & $\% 11$ \\
\hline KSS $\rightarrow$ İÇ & .721 & [.308/.509] & 21.927 & .000 & .257 & {$[.182 / .337]$} & 6.628 & .000 & $\% 26$ \\
\hline
\end{tabular}

Not: KSS: çalışanların kurumsal sosyal sorumluluk algısı; DB: duygusal bağl1lık; İÇ: işveren çekiciliği.

Hair ve arkadaşları (2014), kısmi aracılık ortaya çıkması durumunda VAF değerinin ek kanıt olarak sunulması gerektiğini belirtmişlerdir. Buna göre, bu değerin \%80'in üzerinde çıkması durumunda tam aracılık; \%20 ve \%80 arasında çıkması durumunda kısmi aracılık; \%20'nin altında çıkması durumunda aracılıktan söz edilemez. Tablo 3'te yer alan VAF değerleri incelendiğinde, KSS ve duygusal bağlılık ilişkisinde algılanan kurumsal itibarın aracılık etkisinden bahsedilmezken; KSS ve işveren çekiciliği ilişkisinde algılanan kurumsal itibarın kısmi aracılık rolü doğrulanmıştır. Buna göre, $\mathrm{H}_{4 a}$ hipotezi ampirik olarak desteklenemezken, $\mathrm{H}_{4 \mathrm{~b}}$ hipotezi kısmi olarak desteklenmiştir.

\section{SONUÇ ve ÖNERILER}

$\mathrm{Bu}$ çalışmanın temel amacı, otel çalışanlarının KSS algısının işveren çekiciliği ve duygusal bağlılık üzerine etkisinde kurumsal itibarın aracılık rolünü incelemektir. İstanbul'da faaliyet gösteren üç beş yıldızlı otel çalışanlarından elde edilen verilerle yapılan analizler neticesinde, ilk olarak çalışanların KSS algısının kurumsal itibar algısını olumlu bir şekilde etkilediği belirlenmiştir. İkincisi, çalışanların kurumsal itibar algısının hem duygusal bağlılık hem de işveren çekiciliğini olumlu etkilediği belirlenmiştir. Son olarak yapılan aracılık testi sonucunda, çalışanların kurumsal itibar algısı, KSS ve işveren çekiciliği ilişkisinde kısmi aracılık rolü üstlendiği, KSS ve duygusal bağlılık ilişkisinde aracılık rolü üstlenmediği belirlenmiştir.

Çalışanların KSS algısının kurumsal itibar algısı üzerine olumlu etki oluşturduğuna dair elde edilen bulgu, daha önceki araştırma bulgularını teyit etmektedir (Brammer ve Millington, 2005; Lai vd., 2010; Fu vd., 2014; Su vd., 2017). Buna göre, oteller faaliyet gösterdikleri bölgede paydaşlarının yaşam kalitesini arttırıcı ekonomik, sosyal ve çevresel alanda yürüttükleri girişimlerle sadece müşteriler değil, iç müşteri olarak nitelendirilen çalışanlar 
nezdinde prestijli algılanmaktadır. İkincisi, çalışanların kurumsal itibar algısının duygusal bağlılık (Alniacik vd., 2011; Fu vd., 2014; Arıkan vd., 2016) ve işveren çekiciliği (Gatewood vd., 1993; Behrend vd., 2009) üzerine oluşturduğu olumlu etki daha önceki araştırma bulgularını desteklemektedir. Buna göre, iş görenleri işletmeye çekmek ve duygusal anlamda bağlılıklarını kazanmada kurumsal itibar önemli bir rol oynamaktadır. Son olarak, çalışanların kurumsal itibar algısı, KSS ve işveren çekiciliği ilişkisinde üstlendiği kısmi aracılık rolü daha önceki araştırma bulguları ile örtüşmektedir (Behrend vd., 2009; Gürlek ve Tuna, 2019). Buna göre, sosyal sorumluluk faaliyetlerinin, otellerin kurumsal itibarını güçlendirdiği ve bu durumun işletmeyi iş görenler nezdinde çekici kıldığı belirlenmiştir. Bir bütün olarak değerlendirildiğinde, otel işletmeleri tarafından yürütülen sosyal ve çevresel anlamda sorumlu girişimlerin, çalışanlar nezdinde olumlu geri dönüşler elde etmeye katkı sağladığı ortaya konulmuştur.

Araştırmadan elde edilen bulgular doğrultusunda otel işletmelerine yönelik birtakım öneriler geliştirilebilir. Başarının ekonomik çıtılara ek olarak, sosyal ve çevresel anlamda yürütülen girişimlerle ölçüldüğü günümüz iş dünyasında, otel işletmeleri toplumsal menfaati göz önünde bulundurduğunu gösteren ekonomik, sosyal ve çevresel girişimlerle paydaşları nezdinde itibarını arttırabilir. Ekonomik anlamda yerel tedarikçilerle iş birliği yapma, yerel halka istihdam sağlama vb. girişimlerle ekonomik anlamda sorumlu bir otel işletmesi algısı oluşturabilir. Sosyal anlamda, otel işletmeleri yerel kültürün korunup yaşatılmasında, dil ve dini anlamda yozlaşmaların oluşmasına engel olma gibi girişimlerle sosyal anlamda sorumlu bir işletme imajı oluşturabilir. Çevresel anlamda ise, enerji ve su tasarrufu, geri dönüşüm gibi girişimlerle otel işletmeleri doğal çevrenin korunup geliştirilmesine katkı sağlayarak çevreci bir işletme imajı oluşturabilir. Bir bütün olarak değerlendirildiğinde, ekonomik, sosyal ve çevresel alanda sergilenecek sorumlu girişimlerle oteller mevcut çalışanları nezdinde itibarlı bir otel olarak algilanır.

Bunun yanında, oteller çalışanları nezdinde kurumsal itibarını güçlendirip koruduğu müddetçe işveren olarak çekiciliği artacak ve mevcut çalışanlarının duygusal anlamda bağlılığı sağlanacaktır. Özellikle günümüzde yeni işgücü bulma maliyeti ve mevcut çalışanları işletmede tutma ve onlardan maksimum verimlilik almanın önemi hesaba katıldığında (Tracey ve Hinkin, 2008), oteller itibarlarını güçlendirecek stratejiler geliştirip uygulamalıdır. Mevcut çalışmada, bu stratejilerden biri olan kurumsal sosyal sorumluluk faaliyetlerine dikkat çekilmiştir. Günümüzde birçok işletme toplum yararına yürüttüğü girişimlerin, stratejik KSS faaliyeti bünyesinde değerlendirilebileceği hakkında farkındalıktan yoksundur (Jenkins, 2006). Yani otel işletmeleri sosyal ve çevresel anlamda sorumlu girişimlerde bulunmuyor değildir. Aksine yürütülen bu faaliyetlerin taşıdığı stratejik önemin farkında değildir. Otel işletmeleri toplumsal menfaatleri esas tutan girişimleri başta çalışanlarına olmak üzerine diğer paydaşlarına iletecek kurumsal iletişim mekanizmasını oluşturmalıdır. Oteller, yazılı, sözlü ve web tabanlı örgütsel iletişim araçlarını kullanarak KSS faaliyetlerini çalışanlarına iletebilir. Oteller, broşür ve elkitaplarında, afişlerde, duyuru tahtalarında bu faaliyetleri çalışanlarına iletebilir.

Mevcut çalışmada tıpkı diğer çalışmalarda olduğu gibi birtakım kısıtlılıklara sahiptir. İlk olarak, bu çalışmada veriler sadece üç beş yıldızlı otel işletmesinden toplanmıştır. Sonraki araştırmalarda, veri toplanan otel işletme sayısı arttırılabilir. Hatta ağırlama sektöründe faaliyet gösteren farklı alt sektörlerde (otel, restoran, seyahat acenteleri) çalışanlardan veri toplanarak araştırma modelinin geçerliliği test edilebilir. İkincisi, modeli test etmede 
kullanılan analiz tekniği düşük örneklem sayısına uygun olmasına karşın, sonraki araştırmalarda örneklem sayısı arttırılarak model test edilebilir. Üçüncüsü, mevcut çalışmada çalışanların KSS'ye verdikleri geri dönüşler kapsamında sadece işveren çekiciliği ve duygusal bağlılık tutumları incelenmiştir. Sonraki araştırmalarda, iş tatmini, algılanan örgütsel destek gibi tutumlarının yanı sıra, davranış kapsamında örgütsel vatandaşlık davranışı modele dahil edilip test edilebilir. Son olarak, modelde farklılaştırıcı değişken olarak sosyal sorumluluk farkındalık düzeyi (Tsai vd., 2014) ya da KSS faaliyetlerine yapılan yüklemeler (bkz. Vlachos vd., 2013) test edilerek daha geniş bir bakış açısı kazandırılabilir.

\section{KAYNAKÇA}

AGUINIS, H., \& GLAVAS, A. (2012). "What We Know and Don't Know About Corporate Social Responsibility: A Review and Research Agenda". Journal of Management, 38(4): 932-968.

ALLEN, N. J., \& MEYER, J. P. (1990). "The Measurement and Antecedents of Affective, Continuance and Normative Commitment to the Organization". Journal of Occupational Psychology, 63(1): 1-18.

ALNIACIK, U., CIGGRIM, E., AKCIN, K., \& BAYRAM, O. (2011). "Independent and Joint Effects of Perceived Corporate Reputation, Affective Commitment and Job Satisfaction on Turnover Intentions". Procedia-Social and Behavioral Sciences, 24: 1177-1189.

ARIKAN, E., KANTUR, D., MADEN, C., \& TELCI, E. E. (2016). "Investigating The Mediating Role of Corporate Reputation on the Relationship between Corporate Social Responsibility and Multiple Stakeholder Outcomes". Quality \& Quantity, 50(1): 129149.

AVRUPA KOMISYONU (Commission of the European Communities) (2001). "Promoting a European Framework for Corporate Social Responsibilities”. Brussels.

BARNETT, M. L., JERMIER, J. M., \& LAFFERTY, B. A. (2006). “Corporate Reputation: The Definitional Landscape". Corporate Reputation Review, 9(1): 26-38.

BARON, R. M., \& KENNY, D. A. (1986). "The Moderator-Mediator Variable Distinction in Social Psychological Research: Conceptual, Strategic, and Statistical Considerations". Journal of Personality and Social Psychology, 51(6): 1173.

BARTELS, J., PRUYN, A., \& DE JONG, M. (2009). "Employee Identification before and after an Internal Merger: A Longitudinal Analysis”. Journal of Occupational and Organizational Psychology, 82(1): 113-128.

BEHREND, T. S., BAKER, B. A., \& THOMPSON, L. F. (2009). "Effects of ProEnvironmental Recruiting Messages: The Role of Organizational Reputation". Journal of Business and Psychology, 24(3): 341-350.

BERTHON, P., EWING, M., \& HAH, L. L. (2005). "Captivating Company: Dimensions of Attractiveness in Employer Branding". International Journal of Advertising, 24(2): 151-172. 
BOĞAN, E., \& DEDEOĞLU, B. B. (2017). "The Effects of Perceived Behavioral Integrity of Supervisors on Employee Outcomes: Moderating Effects of Tenure". Journal of Hospitality Marketing and Management, 26(5): 511-531.

BOĞAN, E., \& DEDEOĞLU, B. B. (2019). “The Effects of Hotel Employees' CSR Perceptions on Trust in Organization: Moderating Role of Employees' SelfExperienced CSR Perceptions". Journal of Hospitality and Tourism Insights, 2(4): 391-408.

BOĞAN, E., ÇALIŞKAN, C., \& DEDEOĞLU, B. B. (2018a). "Turizm Yazınında Kurumsal Sosyal Sorumluluk: Türkiye'de Yapılan Çalışmaların Bibliyometrik Analizi”. Turizm Akademik Dergisi, 5(2): 47-62.

BOĞAN, E., TÜRKAY, O., \& DEDEOĞLU, B. B. (2018b). "Perceived Corporate Social Responsibility and Job Satisfaction: The Mediator Role of Organizational Identification". International Journal of Business and Management Studies, 10(2): 51 67.

BRAMMER, S., \& MILLINGTON, A. (2005). “Corporate Reputation and Philanthropy: An Empirical Analysis". Journal of Business Ethics, 61(1): 29-44.

BUONOCORE, F. (2010). "Contingent Work in the Hospitality Industry: A Mediating Model of Organizational Attitudes”. Tourism Management, 31(3): 378-385.

CABLE, D. M., \& TURBAN, D. B. (2003). "The Value of Organizational Reputation in the Recruitment Context: A Brand-Equity Perspective”. Journal of Applied Social Psychology, 33(11): 2244-2266.

CARROLL, A. B. (1979). "A Three-dimensional Conceptual Model of Corporate Performance". Academy of Management Review, 4(4): 497-505.

CARROLL, A. B. (1993). "Business and Society: Ethics and Stakeholder Management". South-Western Publishing Co., 2nd edition, Ohio, USA.

COHEN, J. (1988). "Statistical Power Analysis For The Behavioral Sciences”. Mahwah, NJ: Lawrence Erlbaum.

DAVIS, K. (1967). "Understanding the Social Responsibility Puzzle". Business Horizons, 10(4): 45-50.

DAVIS, K., \& BLOMSTROM, R. L. (1975). "Business and Society: Environment and Responsibility". McGraw-Hill, 3rd edition, New York.

DE GROSBOIS, D. (2012). "Corporate Social Responsibility Reporting by the Global Hotel Industry: Commitment, Initiatives and Performance". International Journal of Hospitality Management, 31(3): 896-905.

DONIA, M. B., RONEN, S., SIRSLY, C. A. T., \& BONACCIO, S. (2019). "CSR by Any Other Name? The Differential Impact of Substantive and Symbolic CSR Attributions on Employee Outcomes". Journal of Business Ethics, 1-21.

DUTTON, J. E., DUKERICH, J. M., \& HARQUAIL, C. V. (1994). “Organizational Images and Member Identification”. Administrative Science Quarterly, 239-263. 
ERTUNA, B., KARATAS-OZKAN, M., \& YAMAK, S. (2019). "Diffusion of Sustainability and CSR Discourse in Hospitality Industry: Dynamics of Local Context". International Journal of Contemporary Hospitality Management.

FORNELL, C., \& LARCKER, D. F. (1981). "Evaluating Structural Equation Models with Unobservable Variables and Measurement Error". Journal of Marketing Research, 18(1): 39-50.

FREEMAN, R. E. (1984). "Strategic management: A Stakeholder Approach". Pitman Publishing, Toronto.

FRIEDMAN, M. (1962). "The Social Responsibility of Business is to Increase its Profits". New York Times, September, 126.

FU, H., LI, Y., \& DUAN, Y. (2014). "Does Employee-Perceived Reputation Contribute to Citizenship Behavior? The Mediating Role of Organizational Commitment". International Journal of Contemporary Hospitality Management, 26(4): 593-609.

GATEWOOD, R. D., GOWAN, M. A., \& LAUTENSCHLAGER, G. J. (1993). "Corporate Image, Recruitment Image And Initial Job Choice Decisions". Academy of Management Journal, 36(2): 414-427.

GEISSER, S. (1974). “A Predictive Approach to the Random Effects Model”, Biometrika, 61:101-107.

GOND, J. P., EL AKREMI, A., SWAEN, V., \& BABU, N. (2017). “The Psychological Microfoundations of Corporate Social Responsibility: A Person-Centric Systematic Review". Journal of Organizational Behavior, 38(2): 225-246.

GREENING, D. W., \& TURBAN, D. B. (2000). "Corporate Social Performance as A Competitive Advantage in Attracting a Quality Workforce". Business \& Society, 39(3): 254-280.

GURSOY, D., BOĞAN, E., DEDEOĞLU, B. B., \& ÇALIŞKAN, C. (2019). "Residents' Perceptions of Hotels' Corporate Social Responsibility Initiatives and its İmpact on Residents' Sentiments to Community and Support for Additional Tourism Development”. Journal of Hospitality and Tourism Management, 39: 117-128.

GÜRLEK, M., \& TUNA, M. (2019). "Corporate Social Responsibility and Work Engagement: Evidence from The Hotel Industry". Tourism Management Perspectives, 31: 195-208.

GÜRLEK, M., DÜZGÜN, E., \& MEYDAN UYGUR, S. (2017). "How Does Corporate Social Responsibility Create Customer Loyalty? The Role of Corporate Image". Social Responsibility Journal, 13(3): 409-427.

HAIR, JOSEPH, F., HULT, G. M., RINGLE, C. M., \& SARSTEDT, M. (2014). “A Primer on Partial Least Squares Structural Equation Modeling (PLS-SEM)”. Thousand Oaks: SAGE Publications.

HAIR, JOSEPH, F., HULT, G. M., RINGLE, C. M., \& SARSTEDT, M. (2017). “A Primer on Partial Least Squares Structural Equation Modeling (PLS-SEM)". 2nd edition, SAGE Publications. 
HENSELER, J., RINGLE, C. M., \& SARSTEDT, M. (2015). “A New Criterion for Assessing Discriminant Validity in Variance-Based Structural Equation Modeling”. Journal of the Academy of Marketing Science, 43: 115-135.

HENSELER, J., RINGLE, C. M., \& SINKOVICS, R. R. (2009). "The Use of Partial Least Squares Path Modeling in International Marketing, New Challenges to International Marketing”. Emerald Group Publishing Limited. 277-319.

HESKETT, J. L., JONES, T. O., LOVEMAN, G. W., SASSER, W. E., \& SCHLESINGER, L. A. (1994). "Putting the Service-Profit Chain to Work". Harvard Business Review, 72(2): 164-174.

HSU, K. T. (2012). "The Advertising Effects of Corporate Social Responsibility on Corporate Reputation and Brand Equity: Evidence from the Life Insurance Industry in Taiwan”. Journal of Business Ethics, 109(2): 189-201.

HUANG, M. H., \& CHENG, Z. H. (2016). “Strategies to Enhance Consumers' Identification with A Service Firm”. Journal of Services Marketing, 30(4): 449-461.

JENKINS, H. (2006). "Small Business Champions for Corporate Social Responsibility". Journal of Business Ethics, 67 (3): 241-256.

JOCHIM, T., OTTENBACHER, M. C., \& HARRINGTON, R. J. (2015). "What and How Are Firms in the Quick-Service Restaurant Industry Reporting on Corporate Social Responsibility?”. Journal of Foodservice Business Research, 18(3): 258-286.

JONES, D. A., WILlNESS, C. R., \& GLAVAS, A. (2017). "When Corporate Social Responsibility (CSR) Meets Organizational Psychology: New Frontiers in Micro-CSR Research, and Fulfilling A Quid Pro Quo through Multilevel Insights". Frontiers in Psychology, 8: 520.

KIM, H. L., RHOU, Y., UYSAL, M., \& KWON, N. (2017). "An Examination of the Links Between Corporate Social Responsibility (CSR) and its Internal Consequences". International Journal of Hospitality Management, 61: 26-34.

KIM, S. B., \& KIM, D. Y. (2016). "The Impacts of Corporate Social Responsibility, Service Quality, and Transparency on Relationship Quality and Customer Loyalty in the Hotel Industry". Asian Journal of Sustainability and Social Responsibility, 1(1): 39.

KORSCHUN, D., BHATTACHARYA, C. B., \& SWAIN, S. D. (2014). “Corporate Social Responsibility, Customer Orientation, and the Job Performance of Frontline Employees". Journal of Marketing, 78(3): 20-37.

LAI, C. S., CHIU, C. J., YANG, C. F., \& PAI, D. C. (2010). "The Effects of Corporate Social Responsibility on Brand Performance: The Mediating Effect of Industrial Brand Equity and Corporate Reputation”. Journal of Business Ethics, 95(3): 457-469.

LANGE, D., LEE, P. M., \& DAI, Y. (2011). “Organizational Reputation: A Review”. Journal of Management, 37(1): 153-184.

LEE, S., \& HEO, C. Y. (2009). "Corporate Social Responsibility and Customer Satisfaction among US Publicly Traded Hotels and Restaurants". International Journal of Hospitality Management, 28(4): 635-637. 
MAIGNAN, I., \& FERRELL, O. C. (2001). "Corporate Citizenship as A Marketing Instrument-Concepts, Evidence and Research Directions". European Journal of Marketing, 35(3/4): 457-484.

MEYER, J. P., ALLEN, N. J., \& SMITH, C. A. (1993). “Commitment to Organizations and Occupations: Extension and Test of a Three-Component Conceptualization". Journal of Applied Psychology, 78(4): 538-551.

NITZL, C., ROLDAN, J. L., \& CEPEDA, G. (2016). "Mediation Analysis in Partial Least Squares Path Modeling”. Industrial Management \& Data Systems, 116(9): 1849-1864.

PANAGOPOULOS, N. G., RAPP, A. A., \& VLACHOS, P. A. (2016). "I Think They Think We are Good Citizens: Meta-Perceptions as Antecedents of Employees' Reactions to Corporate Social Responsibility". Journal of Business Research, 69(8): 2781-2790.

PARK, S. Y., \& LEVY, S. E. (2014). “Corporate Social Responsibility: Perspectives of Hotel Frontline Employees”. International Journal of Contemporary Hospitality Management, 26(3): 332-348.

PORTER, L. W., STEERS, R. M., MOWDAY, R. T., \& BOULIAN, P. V. (1974). "Organizational Commitment, Job Satisfaction, and Turnover among Psychiatric Technicians". Journal of Applied Psychology, 59(5): 603-609.

QU, R. (2014). "Market Orientation and Organizational Performance Linkage in Chinese Hotels: The Mediating Roles of Corporate Social Responsibility and Customer Satisfaction”. Asia Pacific Journal of Tourism Research, 19(12): 1399-1416.

RHOU, Y., \& SINGAL, M. (2020). "A Review of The Business Case for CSR in the Hospitality Industry”. International Journal of Hospitality Management, 84: 102330.

RODRÍGUEZ, F. J. G., \& CRUZ, Y. D. M. A. (2007). "Relation between SocialEnvironmental Responsibility and Performance in Hotel Firms". International Journal of Hospitality Management, 26(4): 824-839.

RUPP, D. E., \& MALLORY, D. B. (2015). “Corporate Social Responsibility: Psychological, Person-Centric, and Progressing”. Annu. Rev. Organ. Psychol. Organ. Behav., 2(1): 211-236.

RYNES, S. L. (1991). "Recruitment, Job Choice, and Post-Hire Consequences: A Call for New Research Directions”. İçinde M. D. Dunnette \& L. M. Hough (Eds.), Handbook of Industrial and Organizational Psychology. Palo Alto, CA: Consulting Psychologists Press, 2: 399-444.

SERRA-CANTALLOPS, A., PEÑA-MIRANDA, D. D., RAMÓN-CARDONA, J., \& MARTORELL-CUNILL, O. (2018). "Progress in Research on CSR and the Hotel Industry (2006-2015)”. Cornell Hospitality Quarterly, 59(1): 15-38.

SILTAOJA, M. E. (2006). "Value Priorities as Combining Core Factors between CSR and Reputation-a Qualitative Study". Journal of Business Ethics, 68(1): 91-111.

STONE, M. (1974). "Cross-Validatory Choice and Assessment of Statistical Predictions". Journal of the Royal Statistical Society, 36: 111-147. 
SU, L., HUANG, S. S., \& PEARCE, J. (2018). "How Does Destination Social Responsibility Contribute to Environmentally Responsible Behaviour? A Destination Resident Perspective". Journal of Business Research, 86: 179-189.

SU, L., PAN, Y., \& CHEN, X. (2017). "Corporate Social Responsibility: Findings from the Chinese Hospitality Industry". Journal of Retailing and Consumer Services, 34, 240247.

TAJFEL, H., \& TURNER, J. C. (1985). “The Social Identity Theory of Intergroup Behavior”. İçinde S. Worchel \& W. G. Austin (Eds.), Psychology of intergroup relations (ss. 724). Chicago: Nelson-Hall.

TRACEY, J. B., \& HINKIN, T. R. (2008). "Contextual Factors and Cost Profiles Associated with Employee Turnover”. Cornell Hospitality Quarterly, 49(1): 12-27.

TSAI, Y. H., JOE, S. W., LIN, C. P., \& WANG, R. T. (2014). "Modeling Job Pursuit Intention: Moderating Mechanisms of Socio-Environmental Consciousness". Journal of Business Ethics, 125(2): 287-298.

TURBAN, D. B., \& GREENING, D. W. (1997). “Corporate Social Performance and Organizational Attractiveness to Prospective Employees". Academy of Management Journal, 40(3): 658-672.

VLACHOS, P. A., PANAGOPOUlOS, N. G., \& RAPP, A. A. (2013). "Feeling Good by Doing Good: Employee CSR-Induced Attributions, Job Satisfaction, and the Role of Charismatic Leadership". Journal of Business Ethics, 118(3): 577-588.

ZHAO, X., LYNCH, J. G., \& CHEN, Q. (2010). "Reconsidering Baron and Kenny: Myths and Truths about Mediation Analysis". Journal of Consumer Research, 37: 197206.0(5), 671-679. 